\title{
Laser-TIG Hybrid Welding of Magnesium Alloy T-Joint with Cold Filler Wire
}

\author{
Zhong-lin $\mathrm{Hou}^{1,2, *}$, Chen-bin $\mathrm{Li}^{1}$ and Li-ming Liu ${ }^{1}$ \\ ${ }^{1}$ Key Laboratory of Liaoning Advanced Welding and Joining Technology, School of Materials Science and Engineering, \\ Dalian University of Technology, Dalian 116024, China \\ ${ }^{2}$ Laser Advanced Manufacturing Technology Center; School of Materials Science and Metallurgy, \\ University of Science and Technology Liaoning, Anshan 114051, China
}

The weldability of magnesium alloy T-joint using laser-TIG hybrid welding heat source with cold filler wire was studied in this paper. The effects of welding parameters (wire feeding angle $\alpha$, wire feeding speed $V_{\mathrm{W}}$, welding speed $V$, shielding gas flow rate acts on either of the connect corner $Q_{\mathrm{C}}$, the distance between filler wire and laser beam $D_{\mathrm{LW}}$ ) on weld appearance and penetration were discussed. Results show that highquality magnesium alloy T-joint can be achieved by adjusting the parameters. Shearing test result indicates that shear strength of the T-joint welded by laser-TIG heat source can be as high as $92.3 \%$ of that of base metal. [doi:10.2320/matertrans.M2015011]

(Received January 6, 2015; Accepted May 11, 2015; Published June 26, 2015)

Keywords: magnesium alloy, T-joint, laser-TIG hybrid heat source, weldability

\section{Introduction}

As one of the most promising basic materials categories for the 21 st century, magnesium and its alloys are widely used in automotive, aerospace, aircraft, communication, electronics and other fields for their advantages such as high specific strength, high damping capacity, good castability, and excellent machinability. ${ }^{1-7)}$ Magnesium welding plays an important role in exploiting new application fields. In modern industry, T-joint gains an increasing application because of its significant enhancing effect and perfect reduction effect, such as the typical T-joints of stiffened plates, structural bead, bogie, web-core sandwich panel, etc. ${ }^{8,9)}$ However, most researches paid much attention on lap and butt welding, and little work can be seen to focus on magnesium T-joint welding. ${ }^{10)}$

T-joint welding is usually at the unilateral or bilateral of the contact angle of the strengthening rib and wall panel. ${ }^{11)}$ In unilateral welding, the stress at the joint is always uneven, and large deformation usually occurs after welding. Comparatively, bilateral welding is used more widely because these shortcomings are overcomed. ${ }^{9,12}$ ) Sometimes it is impossible to weld at connect angle because of the limitation of structure and dimension, and thus welding at wall panel surface is inevitable. Tungsten Inert Gas (TIG) welding, Metal Inert Gas (MIG) welding, and Laser Beam (LB) welding are usually used for welding at the contact angle. However, in the case of welding at wall panel surface, due to the limited heat penetrability of arc and the over concentration of laser beam energy, it is difficult to use these methods for T-joint welding. Laser-arc hybrid welding, demonstrated to overcome these shortcomings from both laser and arc, presents some new features, such as deeper welding penetration, better energy distribution, higher energy utilization ratio and welding efficiency. ${ }^{13-17)}$ Therefore, laserTIG hybrid welding can be considered as a suitable method for T-joint welding of magnesium alloy.

In our previous work, the application of hybrid laser-arc welding heat source in T-joint welding was simply attempted.

*Corresponding author, E-mail: dlut_kyo@sina.com
It is found that the laser-arc heat source is suitable for the T-joint welding, and the joint quality can be accepted. However, further results, including the key factors' influence on the welding process and joint quality, were not gained at that time. So, in this paper, the weldability of T-joint with Laser-TIG hybrid welding is detailedly studied. Cold filler wire is adopted to control the excessive penetration, which usually occurs during welding process due to the special structure of T-joint. ${ }^{18}$ ) The paper gives an overview of the investigations on the weldability of magnesium T-joint using laser-arc hybrid welding with cold filler wire. The effects of welding parameters (wire feeding angle $\alpha$, wire feeding speed $V_{\mathrm{W}}$, welding speed $V$, argon gas flow rate of shielding gas acts on either of the connect corner $Q_{\mathrm{C}}$, and the distance between filler wire and laser beam $D_{\mathrm{LW}}$ ) on weld appearance and penetration are presented and discussed. It is thought that this paper can benefit the researcher and works in laser-arc welding area to deeper understand the hybrid heat source and this T-joint welding technology.

\section{Materials and Experimental Procedures}

\subsection{Materials}

AZ31B magnesium alloy sheets were used as the welding material with dimensions of $100 \times 30 \times 1.5 \mathrm{~mm}^{3}$ and $100 \times$ $40 \times 1.5 \mathrm{~mm}^{3}$ for strengthening rib and wall panel, respectively. AZ61 wires with diameter of $1.6 \mathrm{~mm}$ were chosen as the filler material. The chemical compositions of the base metal and filler wire are shown in Table 1.

\subsection{Experimental procedures}

Hybrid welding system is composed of a Nd:YAG laser, a lateral-axial TIG welder, and a wire feeding device. A schematic configuration of the welding is shown in Fig. 1. Multimode laser was used, and the pulsed laser with wavelength of $1.064 \mu \mathrm{m}$ was focused through a lens with $100 \mathrm{~mm}$ focal length. Defocusing distance of the laser beam to the surface of work piece is $-1.0 \mathrm{~mm}$, and spot diameter on the work piece surface is about $0.6 \mathrm{~mm}$. An AC-TIG arc acted behind the laser beam, and the filler wire was ahead of the laser beam. The angle between laser beam axis and the 
Table 1 Chemical compositions (mass\%) of base metal AZ31B and filler wire AZ61.

\begin{tabular}{ccccccccc}
\hline & $\mathrm{Al}$ & $\mathrm{Zn}$ & $\mathrm{Mn}$ & $\mathrm{Si}$ & $\mathrm{Cu}$ & $\mathrm{Ni}$ & $\mathrm{Fe}$ & $\mathrm{Mg}$ \\
\hline $\mathrm{AZ31B}$ & $2.5 \sim 3.5$ & $0.7 \sim 1.3$ & $0.2 \sim 1.0$ & $<0.05$ & $<0.01$ & $<0.001$ & $<0.002$ & $\mathrm{Bal}$ \\
\hline AZ61 & $5.8 \sim 7.2$ & $0.4 \sim 1.5$ & $0.15 \sim 0.5$ & $<0.1$ & $<0.05$ & $<0.005$ & $<0.005$ & $\mathrm{Bal}$ \\
\hline
\end{tabular}

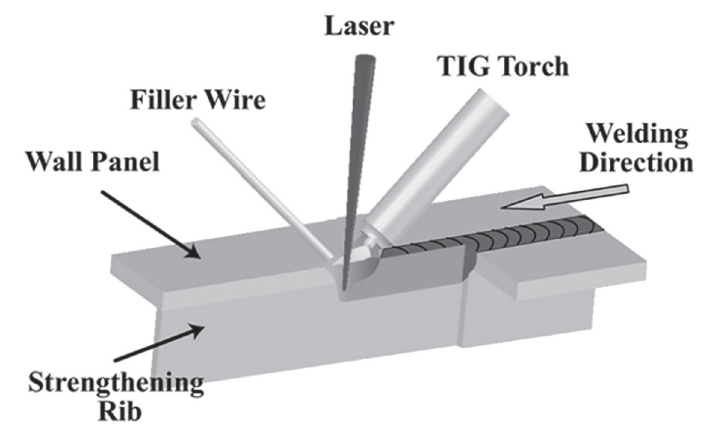

Fig. 1 Schematic diagram of Laser-TIG hybrid welding with cold filler wire.

TIG gun is about $45^{\circ}$. The diameter of tungsten electrode is $3.2 \mathrm{~mm}$, and its tip angle was polished into $15^{\circ}$. The strengthening rib was kept vertically, and the wall panel bear a small force, to avoid the hot crack occurring during the welding process. Before welding, the grease and residues on the base metal surface and the filler wire were removed with acetone, and the oxidation film was removed with emery cloth and stainless steel brush. The treated base metal and filler wire were kept desiccated and used within $24 \mathrm{~h}$ for their effectiveness. Argon with purity of $99.99 \%$ injected from the TIG torch was used to protect molten pool of the top bead, and the back of the bead is also protected by the argon. The main welding parameters are shown in Table 2. After welding, the tensile strengths of the welding joins were tested by an electromechanical universal testing machine at a constant tensile rate of $5 \mathrm{~mm} / \mathrm{min}$. The final results are the average of five specimens. The fracture surfaces were observed by the scanning electron microscopy (SEM). Microhardness test for the T-joint was carried out along a line parallel to the top surface with the distance of $1.5 \mathrm{~mm}$ from the top surface.

\section{Results and Discussion}

3.1 Weldability of T-joint with laser-arc hybrid welding

For single laser welding process, it is hard to achieve satisfied connection between wall panel and strengthening rib. When the laser acting spot deviates a little from the middle line of the strengthening rib, the laser will always cut the wall panel; otherwise, only a very small part of the strengthening rib cross-section is melted because the laserbeam acting zone is extremely small. As shown in Fig. 2(a), the high energy laser heat source can be described as the Rotary-Gauss body heat source, ${ }^{19)}$ and it can be considered as a heat line inserted in workpiece based on our previous work. The laser weld seam always exhibits large depth-to-width ratio. The molten pool shape changes from Line 1 to Line 4
Table 2 Welding parameters in the welding process of T-joint.

\begin{tabular}{|c|c|c|}
\hline Parameters & Values & Units \\
\hline Average power of laser $P$ & 300 & W \\
\hline Laser frequency $f$ & 40 & $\mathrm{~Hz}$ \\
\hline Pulse duration $T$ & 3.4 & $\mathrm{~ms}$ \\
\hline Pulse energy $W$ & 7.5 & $\mathrm{~J}$ \\
\hline Arc current $I$ & 100 & A \\
\hline Electrode height $H$ & 1 & $\mathrm{~mm}$ \\
\hline $\begin{array}{l}\text { Distance between laser beam } \\
\text { and tungsten electrode axis } D_{\mathrm{LA}}\end{array}$ & 1 & $\mathrm{~mm}$ \\
\hline $\begin{array}{l}\text { Distance between laser beam } \\
\text { and filler wire axis } D_{\mathrm{LW}}\end{array}$ & $-1 \sim 1$ & $\mathrm{~mm}$ \\
\hline $\begin{array}{l}\text { Argon flow rate of shielding gas acting } \\
\text { on either of the connect corner } Q_{\mathrm{C}}\end{array}$ & $0 \sim 14$ & $\mathrm{~L} \cdot \min ^{-1}$ \\
\hline Argon flow rate of TIG nozzle $Q_{\mathrm{T}}$ & 10 & $\mathrm{~L} \cdot \min ^{-1}$ \\
\hline $\begin{array}{l}\text { Angle } \alpha \text { of the filler wire axis } \\
\text { to target metal }\end{array}$ & $25 \sim 65$ & $\circ$ \\
\hline $\begin{array}{l}\text { Angle } \beta \text { of the tungsten electrode axis } \\
\quad \text { to target metal }\end{array}$ & 45 & $\circ$ \\
\hline wire feeding speed $V_{\mathrm{W}}$ & $1750 \sim 2050$ & $\mathrm{~mm} \cdot \min ^{-1}$ \\
\hline Welding speed $V$ & $900 \sim 1050$ & $\mathrm{~mm} \cdot \min ^{-1}$ \\
\hline
\end{tabular}
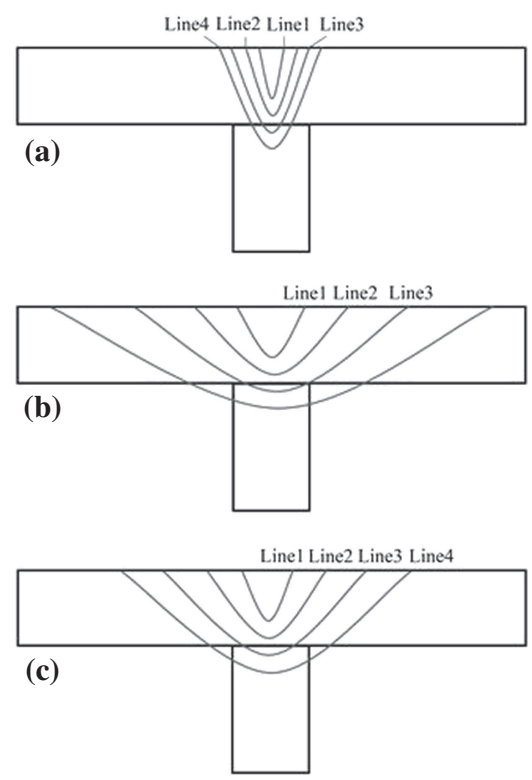

Fig. 2 Model of the effects of different heat sources on T-joint structure: (a) single laser heat source; (b) single TIG heat source; (c) laser-TIG hybrid heat source.

with the increase of heat input, and the width is so narrow when the penetration is acceptable. For single TIG welding, the TIG is described as the Gauss surface heat source and the heat transmits along the surface of workpiece, thus the penetration is shallow and the molten pool is usually wide. As shown in Fig. 2(b), when arc current is constant and the welding speed is relatively high, the shape of molten pool is shown as Line 1 and it changes in the sequence of Line 2, Line 3 and Line 4 with the decreasing welding speed. At high welding speeds, the strengthening rib can hardly be melted due to the weakly penetrability of TIG arc. On the contrary, the molten pool is too large and the surface tension cannot bear so much liquid metal, therefore burn through happens. For laser-TIG hybrid welding, laser can induce 

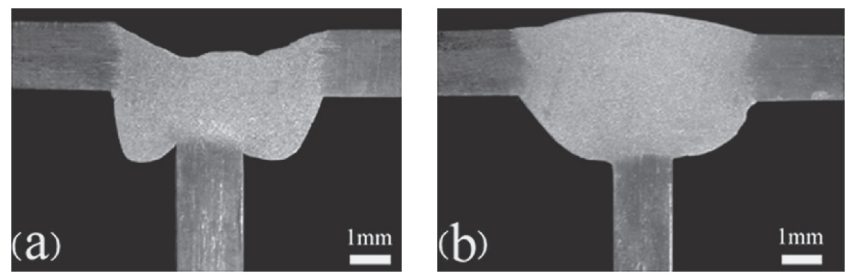

Fig. 3 Typical weld appearance of T-joints welded by laser-TIG hybrid welding and laser-TIG hybrid welding with cold filler wire: (a) laser-TIG hybrid welding; (b) laser-TIG hybrid welding with cold filler wire.

arc and enhance arc penetrability and stability, and the penetration of weld seam can increases remarkably. ${ }^{20-22)}$ Compared with TIG welding, the weld width increases more slowly because the penetration increase is uniform, and it is easy to achieve a narrow weld seam because the penetrations are the same as laser-TIG hybrid welding, as shown in Fig. 2. Besides, on one hand, the high temperature charged particle in laser plasma accesses the arc through current-conducting channel of laser and TIG arc, thus both ionization degree and temperature of arc increase based on the principle of minimum voltage. The arc capacity shrinks necessarily in order to reduce energy loss and the stability is increased; on the other hand, the laser keyhole can offer stable cathode spot for arc and impede the shift of arc root.

\subsection{Typical weld appearance of the joints}

Figure 3 shows the cross-sections of the weld seams of laser-TIG hybrid welding with and without cold filler wire under the same welding conditions. For the laser-TIG hybrid welding seam in Fig. 3(a), an excessive penetration obviously exhibits due to the evaporation and lose of low melting point elements of $\mathrm{Mg}$ and $\mathrm{Al}$. Moreover, the region near the right contact angle is empty, which could be filled by a small amount of liquid metal leaking down from the wall panel. In order to avoid this, welding material must be added. For the seam of laser-TIG hybrid welding with cold filler wire in Fig. 3(b), a stated reinforcement is achieved obviously because of the filler wire addition. In addition, the filler wire can make up the loss of alloy element $\mathrm{Al}$, $\mathrm{Zn}$, etc., improve microstructure, and thus enhance the mechanical property of the weld seam. With the optimized experimental parameters, full-penetration welding joint can be gained with homogeneous and uniform ripples forming on the top surface of the welding seam, as shown in Fig. 4.

\subsection{Effect of distance between laser beam and filler wire axis}

During laser-TIG hybrid welding with cold filler wire, the distance between laser beam and filler wire axis $D_{\mathrm{LW}}$ is one of the most sensitive parameters, even though it can only change in a very small range. $D_{\mathrm{LW}}$ is positive $(+)$ when the filler wire axis is in front of laser beam, or else it is negative $(-)$. In order to ensure the experimental accuracy, all the parameters except $D_{\mathrm{LW}}$ were fixed $\left(Q_{\mathrm{C}}\right.$ is $0, \alpha$ is $45^{\circ}, V_{\mathrm{W}}$ is 1875 $\mathrm{mm} \cdot \mathrm{min}^{-1}, V$ is $\left.975 \mathrm{~mm} \cdot \mathrm{min}^{-1}\right)$. When $D_{\mathrm{LW}}$ is larger than $+0.5 \mathrm{~mm}$, the sphere of laser leaded arc action is small, and $D_{\text {LW }}$ is so large that the filler wire can not be melted adequately. The cold filler wire touches the workpiece and

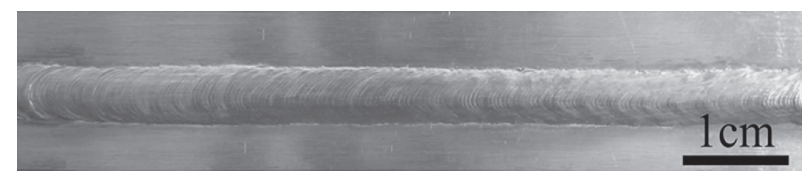

Fig. 4 Macroscopic configuration of the welded joint laser-TIG hybrid welding with cold filler wire

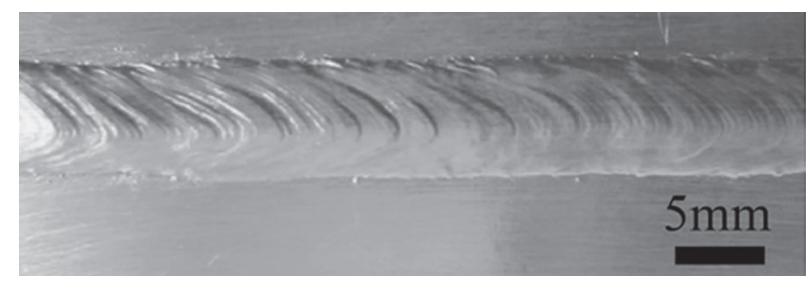

Fig. 5 Seam in mountain ridge shape $\left(D_{\mathrm{LW}}<0.7 \mathrm{~mm}\right)$.

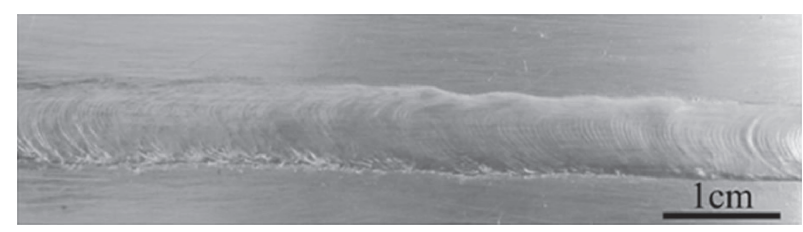

Fig. 6 Weld appearance of T-joint $\left(\alpha>55^{\circ}\right)$.

change direction, which affects the stability of arc and blocks out the laser and compels the welding process to finish. When $D_{\text {LW }}$ is less than $-0.7 \mathrm{~mm}$, the laser beam acts directly on the filler wire and a mass of sputtering occurs, the strengthening rib can not be melted because of the penetrability of arc is weak without the attraction and compression of laser. Moreover, the filler wire melts quickly by consuming too much heat, so that only a small amount of heat can be transmitted to the base metal. Therefore, the wall panel and strengthening rib can not be completely connected. In addition, the unpliable weld seam and the loose ripple result from the incomplete spread of the molted metal, and under this condition, the filler wire is so close to the laser and the arc that big droplet forms. The big droplets cool down rapidly with decreasing flowing ability, and thus forms mountain ridge seam as shown in Fig. 5. When $D_{\mathrm{LW}}$ is in the range of $-0.7 \mathrm{~mm}$ to $+0.5 \mathrm{~mm}$, the penetration and weld appearance are almost the same.

3.4 Effect of angle $\alpha$ of the filler wire axis to target metal

In order to investigate the effect of angle $\alpha$ between filler wire axis and target metal on weld appearance and penetration, other parameters were kept constant $\left(D_{\mathrm{LW}}\right.$ is $0 \mathrm{~mm}, Q_{\mathrm{C}}$ is $0, V_{\mathrm{W}}$ is $1875 \mathrm{~mm} \cdot \mathrm{min}^{-1}, V$ is $\left.975 \mathrm{~mm} \cdot \mathrm{min}^{-1}\right)$. Experimental results show that $\alpha$ only affects weld appearance. The weld seam is curved and accidented when $\alpha$ is larger than $55^{\circ}$, as shown in Fig. 6, because apex of the filler wire is relatively far away from workpiece surface, and the directive property of the feeding wire becomes worse and the droplet can't transit rapidly. The shielding gas from TIG nozzle agitates the droplet and it can not drop towards a stationary direction. Besides, the wobbly droplet will result in an unstable arc and then form curve welded seam. When $\alpha$ 
is less than $55^{\circ}$, the droplet can transit to the weld pool homogeneously and stably, and thus a good weld seam forms.

\subsection{Effect of wire feeding speed $V_{W}$}

During laser-TIG hybrid welding with cold filler wire, $V_{\mathrm{W}}$ must match with other parameters. Since laser power and arc current are fixed, $V_{\mathrm{W}}$ must match with welding speed $V$. Assuming that all the melted filler wire can transit to the molten pool in welding process, we can calculate the wire feeding speed $V_{\mathrm{W}}$ according to law of mass conservation.

$$
k \cdot s \cdot V_{\mathrm{W}}=\frac{\pi}{4} \cdot d^{2} \cdot V
$$

where $k$ is the shape factor decided by requirement of reinforcement.

$s$ is the filling area considered as semicircle with the semidiameter of slab thickness, and $d$ is the diameter of the filling wire. Based on eq. (1), $V_{\mathrm{W}}$ can be calculated approximately when $V$ is fixed. Further, $k$ can be expressed as

$$
k=1+t / t_{0},
$$

where $t$ is the height of weld reinforcement and $t_{0}$ is the plate thickness. In this research, $k$ is approximately to $1.2 \sim 1.3$. Excessive penetration is hard to be overcome when $V_{\mathrm{W}}$ is slow. On the other hand, excessive high reinforcement usually forms when $V_{\mathrm{W}}$ is large. In addition, the droplets translating fast under continuous laser radiation result in the spatters.

Wire feeding speed $V_{\mathrm{W}}$ has an obvious effect on the height of reinforcement $H_{\mathrm{R}}$ and penetration $H_{\mathrm{p}}$. As shown in Fig. 7, with the increase of $V_{\mathrm{W}}, H_{\mathrm{R}}$ increases, while $H_{\mathrm{p}}$ decreases. With the increase of $V_{\mathrm{W}}$, the feeding wire is upright and it is heated by both arc and laser, molted capacity of the filler wire increases per unit time and then higher reinforcement forms due to the fixed welding speed $V$. In this process, the consumed quantity of heat by melting filler wire increases and quantity of heat for melting base metal decreases correspondingly, thus $H_{\mathrm{p}}$ decreases.

\subsection{Effect of flow rate of argon shielding gas acting on both of the connect corner $Q_{\mathrm{C}}$}

Flow rate of the Argon shielding gas acting on both of the connect corner $Q_{\mathrm{C}}$ has an obvious effect on $H_{\mathrm{p}}, H_{\mathrm{r}}, W$. As shown in Fig. 8, the weld width $W$ and penetration $H_{\mathrm{p}}$ increase first and then decrease with the increase of argon flow rate, while $H_{\mathrm{r}}$ decreases first and then increases. On one hand, the high speed cold argon acts on both the wall panel and the strengthening rib, and it increases the temperature gradient along the vertical strengthening rib and the horizontal wall panel, so the heat transits along the two directions rapidly, and base metal is melted towards vertical and horizon rapidly. On the other hand, argon reduces surface tension and flow ability of the liquid metal, and heat can not dissipate quickly, thus the width and penetration increase. However, the high speed cold argon can take large quantity of heat when the argon flow rate is higher than $8 \mathrm{~L} / \mathrm{min}$, causing the decreased width and penetration. When the width and penetration are large, the area of weld seam is large and more metal is needed to fill up the absence of base metal. Accordingly, the height of reinforcement decreases first and then increases.

\subsection{Mechanical properties}

Magnesium alloy T-joints by hybrid welding with and without cold filler wire were prepared, and their mechanical properties were tested by a tensile machine. The force diagram is shown in Fig. 9. The fractographys show $45^{\circ}$ shear fracture occurring at the heat affect zone of the wall panel. It is found that the average shear strength is $119.0 \mathrm{MPa}$

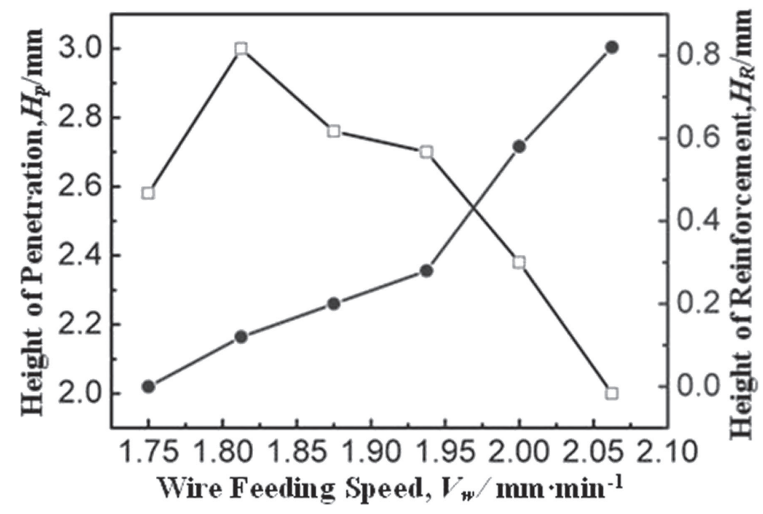

Fig. 7 Effect of wire feeding speed $V_{\mathrm{W}}$ on the penetration $H_{\mathrm{p}}$ and the height of reinforcement $H_{\mathrm{r}}$.

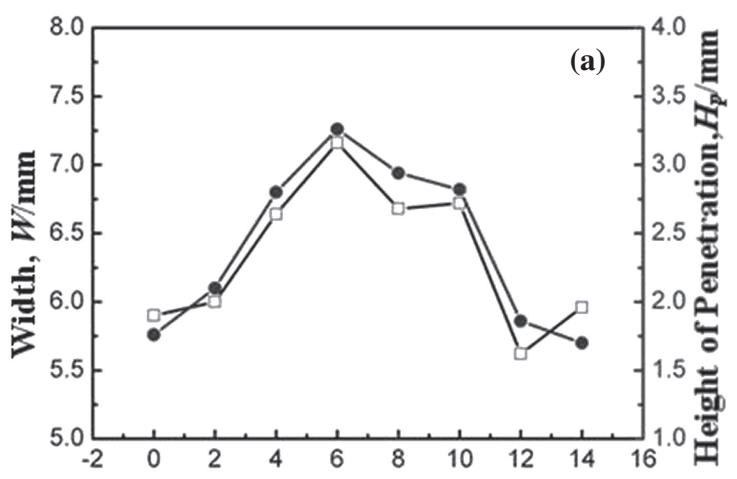

Argon Flow Rate of Shielding Gas Acts on either of the Connect Corner, $Q_{c} / L \cdot m^{-1}$

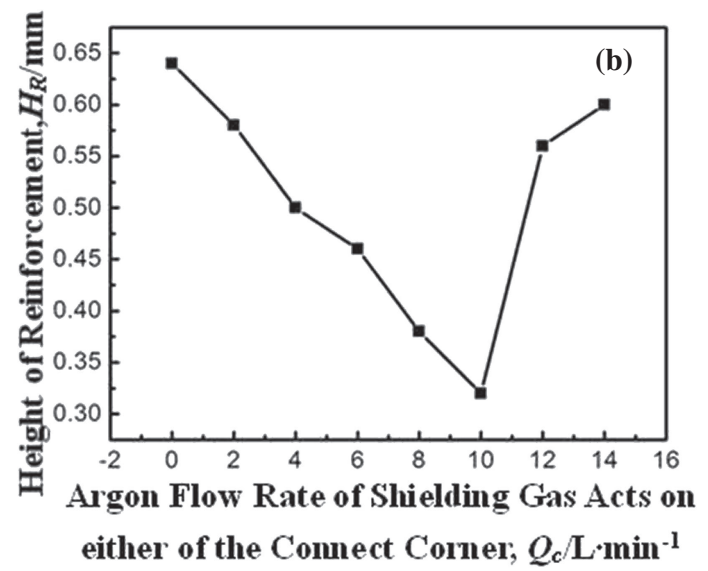

Fig. 8 Effect of connect corner $Q_{\mathrm{C}}$ on $H_{\mathrm{p}}, H_{\mathrm{r}}, W$ : (a) $W, H_{\mathrm{p}}$; (b) $Q_{\mathrm{C}}$. 


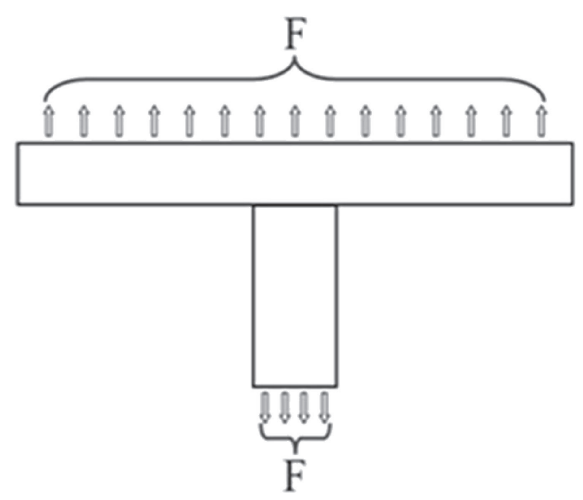

Fig. 9 Force diagram of T-joint in shear strength test.

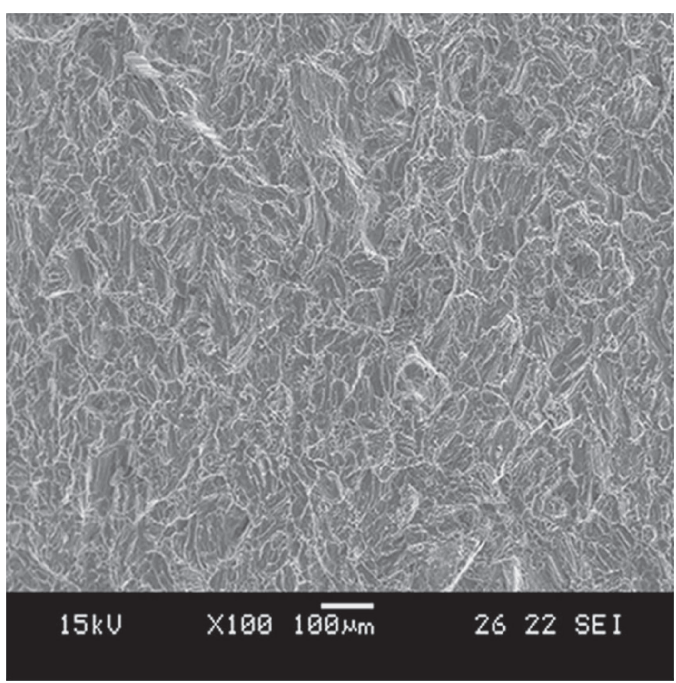

Fig. 10 SEM analysis of T-joint fracture pattern.

(92.3\% of base metal) for laser-TIG hybrid welding with cold filler wire, while it is $100.0 \mathrm{MPa}$ for laser-TIG hybrid welding without cold filler wire. From the SEM fracture pictures shown in Fig. 10, it is found the fracture has the low brittleness. A large amount of honeycomb indicates a mixture fracture, where gliding fracture is the dominate fracture mode, accompanied by minor brittle fracture. A microhardness test was carried out on the weld joint, and Fig. 11 presents the results. It can be seen from Fig. 11 that compared with base metal and heat affected zone, the fusion zone of the T-joint possesses the lowest microhardness $\left(63.3 \mathrm{H}_{\mathrm{v}}\right.$ in average).

\section{Conclusions}

(1) It is suitable to weld magnesium T-joints using LaserTIG hybrid heat source due to excellent energy distribution of the heat source. The joints are well shaped when the heat source acts on the top surface of the workpiece. But underfill is the main defect due to the evaporation loss of base metal and the special structure of T-joint. The underfill can be avoided by adding cold filler wire. Continuous and compact ripples form on the top surface of the fully penetrated weld seam.
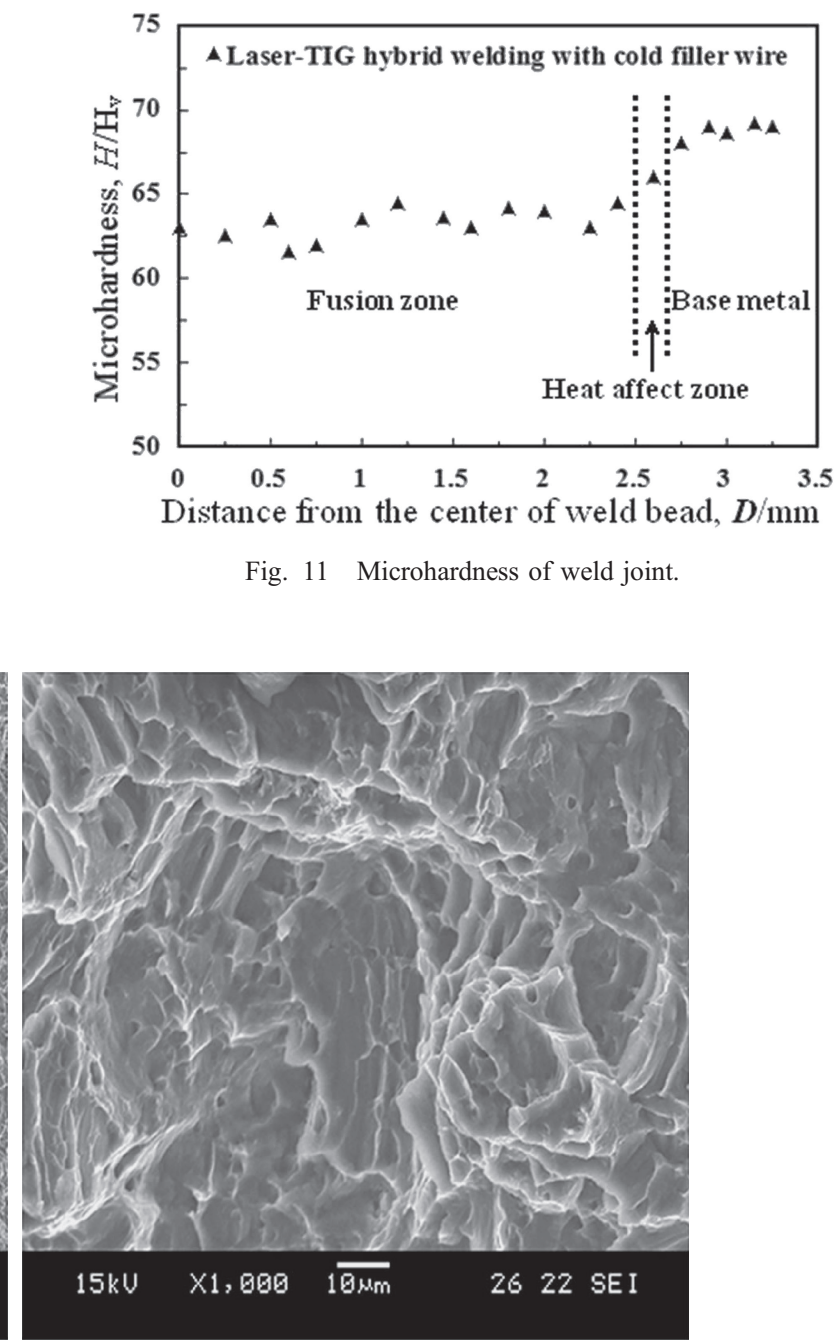

Fig. 11 Microhardness of weld joint.

(2) Due to the special structure of the T-joint, welding parameters (wire feeding angle $\alpha$, wire feeding speed $V_{\mathrm{W}}$, flow rate of argon shielding gas acting on either of the fillet $Q_{\mathrm{F}}$, the distance between filler wire and laser beam $D_{\mathrm{LW}}$ ) have great effects on weld appearance and penetration. In this experimental, the best parameters are listed below: $\alpha$ is $45^{\circ}, V_{\mathrm{W}}$ is $1875 \mathrm{~mm} \cdot \mathrm{min}^{-1}, V$ is $975 \mathrm{~mm} \cdot \mathrm{min}^{-1}$ and $D_{\mathrm{LW}}$ ranges from $-0.7 \mathrm{~mm}$ to $+0.5 \mathrm{~mm}$. Under the optimized parameters, shear strength of the laser-arc welded T-joint reaches $92.3 \%$ of that of the base material. The fusion zone of the joint has the lowest microhardness.

\section{Acknowledgement}

The authors gratefully acknowledge the sponsorships from Program for Changjiang Scholars, the National Natural Science Foundation of China (grant No. 11375038) and the Natural Science Foundation of USTL.

\section{REFERENCES}

1) S. Ignat, P. Sallamand, D. Grevey and M. Lambertin: Appl. Surf. Sci. 233 (2004) 382-391. 
2) J. Hirsch and T. Al-Samman: Acta Mater. 61 (2013) 818-843.

3) F. Czerwinski: Corros. Sci. 86 (2014) 1-16.

4) G. Mahendran, V. Balasubramanian and T. Senthilvelan: Int. J. Adv. Manuf. Technol. 42 (2009) 689-695.

5) T. T. Wan, Z. X. Liu, M. Z. Bu and P. C. Wang: Corros. Sci. 66 (2013) 33-42.

6) V. A. Hosseini, H. Aashrui and A. Kokabi: Trans. Nonferrous Met. Soc. China 23 (2013) 2585-2590.

7) Y. Q. Zhang, P. Wen and J. G. Shan: J. Laser Appl. 22 (2010) 92-98

8) J. Romanoff, H. Remes, G. Socha, M. Jutila and P. Varsta: Thin Wall. Struct. 45 (2007) 453-462.

9) T. L. Teng, C. P. Fung, P. H. Chang and W. C. Yang: Int. J. Pres. Ves. Pip. 78 (2001) 523-538.

10) G. X. Xu, C. S. Wu, X. Z. Ma and X. Y. Wang: Acta Metall. Sin. 26 (2013) 352-360.

11) F. P. Brennan, P. Peleties and A. K. Hellier: Int. J. Fatigue 22 (2000)
573-584.

12) P. Wang and K. M. Ewing: Weld. J. 73 (1994) 209-217.

13) W. M. Steen: J. Appl. Phys. 51 (1980) 5636-5641.

14) M. Gao, X. Y. Zeng, J. Yan and Q. W. Hu: Appl. Surf. Sci. 254 (2008) 5715-5721.

15) X. Hao and G. Song: IEEE Trans. Plasma Sci. 37 (2009) 76-82.

16) C. Li, M. Kutusna, T. Simizu and K. Horio: Mater. Des. 30 (2009) 109114.

17) C. B. Li and L. M. Liu: Int. J. Adv. Manuf. Technol. 65 (2013) 27-34.

18) A. Kudzys: J. Constr. Steel. Res. 62 (2006) 1238-1243.

19) L. M. Liu, M. S. Chi, G. Song and J. F. Wang: China J. Mech. Eng. 42 (2006) 82-85.

20) J. Q. Gao, G. L. Qin, J. L. Yang, J. G. He, T. Zhang and C. S. Wu: Trans. Nonferrous Met. Soc. China 21 (2011) 423-428.

21) L. M. Liu and M. H. Chen: Opt. Laser. Eng. 49 (2011) 1224-1231.

22) X. D. Qi and G. Song: Mater. Des. 31 (2010) 605-609. 